\title{
ECONOMICAL ACTIVITY OF THE POLISH POPULATION
}

\author{
Beata Bieszk-Stolorz, Ph.D. \\ Iwona Markowicz, Ph.D. \\ University of Szczecin \\ Faculty of Economics and Management \\ Department of Econometrics and Statistics \\ Mickiewicza 64, 71-101 Szczecin, Poland \\ e-mail:beatus@wneiz.pl \\ e-mail: imarkowicz@wneiz.pl
}

Received 9 June 2014, Accepted 15 December 2014

\begin{abstract}
The aim of the article is to examine the impact of a job seeker's gender, education, age on their employment odds in Poland in 2011. The research includes Polish population which was economically active and aged 15 and more in 2011 (17,951 thousand people). The research tool was a logit model. The starting point for the analysis was the construction of a model that related employment to gender only. Then other models with many explanatory variables were constructed. Since the gender related odds ratios that have been determined for the sake of those models are interpreted under the assumption that the other variables are constant, it indicates that the women's and men's odds ratio remains the same in urban and rural areas, on every education level and in every age group. But in reality it is not true. This is why we estimated the models that contained only one explanatory variable (gender) for individual subgroups and models with the interactions.
\end{abstract}

Keywords: logit model, economical activity, employed and unemployed persons.

JEL classification: C14, J21, E24. 


\section{Introduction}

In 2011 the economical activity rate in Poland reached 56.3\%, the employment rate $50.8 \%$, while the unemployment rate was $9.7 \%$. The above rates are different for men and women. The proportion of economically active men was higher and amounted to $64.7 \%$ (in comparison to $48.7 \%$ women). Also, the share of the employed men was larger at $58.9 \%$ than that of the employed women $(43.4 \%)$. On the other hand, the women's unemployment rate overgrew the men's ( $9.9 \%$ and $8.8 \%$ respectively). The aim of the article was to review the employment odds for men and women. With a view to this we used the logit model with one and many explanatory variables as well as with the interactions, paying particular attention to the differences among the estimated parameters of individual models. The study covered economical activity of the Polish population aged 15 and more in 2011. The article is a part of the Ministry of Science and Higher Education grant No. N N111 273538 (2010-2012).

\section{The research method}

In order to examine the impact of a gender factor on the employment odds we applied the logistic regression model. This is the model which is used most often in socio-economic researches ${ }^{1}$. Theoretical bases were widely discussed by Hosmer and Lemeshow, Kleinbaum and Klein, Cramer, while Agresti and Wiśniewski pointed it out among the researching methods of quality phenomena ${ }^{2}$.

Many economic and social phenomena have a qualitative character. Dependence analysis is conducted on the basis of models different than in the case of quantitative variables. The logistic regression model may be quoted as an example. It accounts for the dependence of a given event on factors determining this event. Variants of qualitative variables are defined. They may differ in character, but are usually dichotomous.

According to Fijorek and Sokołowski ${ }^{3}$, logistic regression is one of the most popular techniques used to describe the relationship between a binary dependent variable and a set of independent variables. However, the application of logistic regression to small data sets is often hindered by the complete or quasicomplete separation. Logistic regression is a commonly used tool to describe the relationship between a binary outcome variable and a set of explanatory variables. It is routinely employed in many fields, e.g., medicine, social sciences, economics. The popularity of logistic regression stems mainly from its mathematical convenience and the relative ease of interpretation in terms of odds ratios. The main goal of the paper these authors are to introduce the STATISTICA macro, which performs firth-type logistic regression. 
This model is used usually in the research into unemployment in various nations, e.g.: Meyer - USA, Richard - France, Kostaki and Ioakimoglou - Greece, Lučkaničová, Ondrušeková and Rešovský - Slovakia, Jarosova et al - Czech Republic, Markowicz and Stolorz, Bieszk-Stolorz - Poland ${ }^{4}$.

In Meyer's paper semiparametric estimation techniques are used and compared to alternative approaches. The semiparametric approach yields more plausible estimates and provides useful diagnostics

Richard's study is based on an analysis of different methods that can be used to establish a possible discrimination against some young people ( $<33$ years old) of foreign origin who are living in France. According to Richard, logit models are very useful to understand the complexity of effects.

Kostaki's and Ioakimoglou's aim was to investigate the effect of demographic characteristics such as gender, marital status, age and educational level on long-term unemployment. Initially the influence of each of the four demographic characteristics was examined separately without taking into consideration the simultaneous influence of the other characteristics. Subsequently, a more detailed analysis was undertaken of the influence of these characteristics, making use of a statistical model of logistic regression. The application of this model enables us not only to check the statistical significance of each factor exerting influence but also to gauge its intensity. It is moreover a model which makes it possible for us, firstly, to check the likelihood of interactions between the different characteristics; secondly to study the manner in which the characteristics interact; and thirdly to determine the strength of these interactions.

In Lučkaničová’s, Ondrušeková's and Rešovský's paper authors present models based on a statistical modelling approach that explain the effects of selected variables on employment in Slovakia in the years 2005 and 2009. The probability of becoming employed (employability/ odds ratio) was based on individual data. For quantification of the mentioned variables' impact on the dependent variable (employment) logistic regression was applied. The results confirmed a positive effect of work experience and the highest level of education attained on employability. Conversely, in some cases age showed a negative effect on the dependent variable, and to some extent gender also had a significant effect.

In Jarosova's et al study the log-logistic regression model without interactions and with the piecewise linear dependence on age was selected as the best one. The dependence on education and sex was confirmed. 
The logistic model can be expressed in a logit form as:

$$
\operatorname{logit}(p)=\ln \left(\frac{p}{1-p}\right)=\alpha_{0}+\sum_{i=1}^{k} \alpha_{i} x_{i}
$$

where:

$p=P\left(Y=1 \mid x_{1}, x_{2}, \ldots, x_{k}\right)$ - the likelihood of a specific incident to happen,

$x_{i}$ - explanatory variables for $i=1,2, \ldots, k$,

$\alpha_{i}$-regression coefficient for $i=0,1,2, \ldots, k$.

The results are interpreted by means of an expression $\exp \left(\alpha_{i}\right)$ being an odds rate (OR) of employment in a given group in relation to the test group ${ }^{5}$.

Therefore, if any exogenous variable $x_{i}$ increases by a unit (the remaining exogenous variables are not subject to change), odds ratio (OR) can be determined with the use of the following formula:

$$
O R=\frac{P\left(x_{j+1}\right)}{1-P\left(x_{j+1}\right)} \div \frac{P\left(x_{j}\right)}{1-P\left(x_{j}\right)}=\frac{e^{\alpha_{0}} \cdot e^{\alpha_{i} x_{j+1}}}{e^{\alpha_{0}} \cdot e^{\alpha_{i} x_{j}}}=e^{\alpha_{i}\left(x_{j+1}-x_{j}\right)}=e^{\alpha_{i} \cdot 1}=e^{\alpha_{i}}
$$

The logistic model with interactions can be expressed in a logit form as:

where:

$$
\operatorname{logit}(p)=\ln \left(\frac{p}{1-p}\right)=\alpha_{0}+\sum_{i=1}^{k} \alpha_{i} x_{i}+\sum_{i=1}^{k} \sum_{\substack{j=1 \\ i \neq j}}^{k} \alpha_{i j} x_{i} \times x_{j}
$$

$p=P\left(Y=1 \mid x_{1}, x_{2}, \ldots, x_{k}\right)$ - the likelihood of a specific incident to happen,

$x_{i}$ - explanatory variables for $i=1,2, \ldots, k$,

$\alpha_{i}, \alpha_{i j}$ - regression coefficient for $i=0,1,2, \ldots, k, j=0,1,2, \ldots, k,(i \neq j)$.

\section{Logit models of employment}

When analysing the Poles' economical activity in 2011 the authors built four groups of logit models. In all the models they decided on the explanatory variable to be the type of economical activity which has been defined as follows:

$$
Y= \begin{cases}1, & \text { for an employed person } \\ 0, & \text { for an unemployed person }\end{cases}
$$

These are the employment models. 
Explanatory variables are of different types, they are measured in various measurement scales $^{6}$ and need proper coding. Gender variables $(G)$ and the place of residence $(R)$ are dichotomous variables (nominal scale) and have been changed into zero-one false variables. Education (E) and age (A) are multivariate variables. They have been transformed into $n-1$ zero-one false variables (properly 4 and 5). A reference group in this study consisted of individuals with at least lower secondary education and aged 15-24.

The description of the explanatory variables is to be found in Table 1.

Table 1 . The description of explanatory variables in the logit model

\begin{tabular}{|c|c|c|c|}
\hline Independent variable & Value & Groups & $\begin{array}{l}\text { Numbers } \\
\text { (in thous.) }\end{array}$ \\
\hline \multirow{2}{*}{$G$ (gender) } & 0 & Females & 8138 \\
\hline & 1 & Males & 9813 \\
\hline \multirow{2}{*}{$R$ (the place of residence) } & 1 & Urban areas & 11070 \\
\hline & 0 & Rural areas & 6881 \\
\hline \multirow{2}{*}{$E_{1}$ (education) } & 1 & Basic vocational & 5008 \\
\hline & 0 & Other & 1386 \\
\hline \multirow{2}{*}{$E_{2}$ (education) } & 1 & General secondary & 1599 \\
\hline & 0 & Other & 1386 \\
\hline \multirow{2}{*}{$E_{3}$ (education) } & 1 & Post-secondary and vocational secondary & 4911 \\
\hline & 0 & Other & 1386 \\
\hline \multirow{2}{*}{$E_{4}$ (education) } & 1 & Higher & 5046 \\
\hline & 0 & Other & 1386 \\
\hline \multirow{2}{*}{$A_{1}$ (age) } & 1 & $25-34$ & 5319 \\
\hline & 0 & Other & 1632 \\
\hline \multirow{2}{*}{$A_{2}$ (age) } & 1 & $35-44$ & 4504 \\
\hline & 0 & Other & 1632 \\
\hline \multirow{2}{*}{$A_{3}$ (age) } & 1 & $45-54$ & 4095 \\
\hline & 0 & Other & 1632 \\
\hline \multirow{2}{*}{$A_{4}$ (age) } & 1 & $55-59$ & 1570 \\
\hline & 0 & Other & 1632 \\
\hline \multirow{2}{*}{$A_{5}$ (age) } & 1 & 60 years and more & 829 \\
\hline & 0 & Other & 1632 \\
\hline
\end{tabular}

Source: own study based on the data published by the Central Statistical Office (2012) Labour Force Survey in Poland IV Quarter 2011.

The study was carried out in four stages. They contain building the following models:

- with one explanatory variables - gender $(\mathrm{G})$; stage I,

- with two explanatory variables - gender $(G)$ and other variable (place of the residence $-R$, education groups $-E_{i}$ or age groups $-A_{i}$ ); stage II,

- with one explanatory variables - gender $(G)$ in the individual education and age subgroups; stage III, 
- with two explanatory variables - gender $(\mathrm{G})$ and other variable (place of the residence $-R$, education groups $-E_{i}$ or age groups $-A_{i}$ ) and with their interactions; stage IV.

The analysis started with building model where employment were related to gender only (stage I). The following model were built (with relevant parameters):

$$
\operatorname{logit}(p)=2.1061+0.2278 \cdot G
$$

The results of the logit model estimation are to be found in Table 2.

Table 2. Estimated parameters of the employment logit model (stage I)

$$
\chi^{2}=20,447.33, p=0.0000
$$

\begin{tabular}{|l|c|c|c|c|}
\hline \multicolumn{1}{|c|}{$X_{i}$} & $\begin{array}{c}\text { Regression coefficient } \\
\text { estimator }\end{array}$ & Standard error & $p$-value & Odds ratio \\
\hline$\alpha_{0}$ & 2.1061 & 0.0011 & 0.0000 & \\
\hline$G$ & 0.2278 & 0.0016 & 0.0000 & 1.2558 \\
\hline
\end{tabular}

Source: own study (STATISTICA).

The parameter with the variable $G$ is positive, so the men's employment odds are higher than the women's. On stage II further models were constructed where explanatory variables consisted of the following pairs: gender and the place of residence $(G, R)$, gender and education $\left(G, E_{i}\right)$, gender and age $\left(G\right.$ and $\left.A_{i}\right)$. The estimated models have the character:

$$
\operatorname{logit}(p)=2.0776+0.2296 \cdot G+0.0450 \cdot R
$$

$$
\operatorname{logit}(p)=1.4823+0.1616 \cdot G+0.6873 \cdot E_{1}+0.2841 \cdot E_{2}+0.7099 \cdot E_{3}+1.3355 \cdot E_{4}
$$

$$
\begin{aligned}
\operatorname{logit}(p)= & 0.8786+0.2646 \cdot G+1.1669 \cdot A_{1}+1.5701 \cdot A_{2}+1.4886 \cdot A_{3}+ \\
& +1.4949 \cdot A_{4}+2.2009 \cdot A_{5}
\end{aligned}
$$

The results of the logit model estimation are to be found in Table 3 .

Table 3. Estimated parameters of the employment logit models (stage II)

\begin{tabular}{|l|c|c|c|c|}
\hline \multicolumn{1}{|c|}{$X_{i}$} & $\begin{array}{c}\text { Regression coefficient } \\
\text { estimator }\end{array}$ & Standard error & $p$-value & Odds ratio \\
\hline 1 & 2 & 3 & 4 & 5 \\
\hline & \multicolumn{3}{|c|}{$\begin{array}{c}\text { Gender and the place of residence } \\
\chi^{2}=21,203.31, p=0.0000\end{array}$} \\
\hline$\alpha_{0}$ & 2.0776 & 0.0015 & 0.0000 & 1.2581 \\
\hline$G$ & 0.2296 & 0.0016 & 0.0000 & 1.0460 \\
\hline$R$ & 0.0450 & 0.0016 & 0.0000 & \\
\hline
\end{tabular}




\begin{tabular}{|l|c|c|c|c|}
\hline \multicolumn{1}{|c|}{1} & 2 & 3 & 4 & 5 \\
\hline & \multicolumn{4}{|c|}{$\begin{array}{c}\text { Gender and education } \\
\chi^{2}=237,608.80, p=0.0000\end{array}$} \\
\hline$\alpha_{0}$ & 1.4823 & 0.0024 & 0.0000 & \\
\hline$G$ & 0.1616 & 0.0016 & 0.0000 & 1.1754 \\
\hline$E_{1}$ & 0.6873 & 0.0027 & 0.0000 & 1.9883 \\
\hline$E_{2}$ & 0.2841 & 0.0032 & 0.0000 & 1.3285 \\
\hline$E_{3}$ & 0.7099 & 0.0027 & 0.0000 & 2.0338 \\
\hline$E_{4}$ & 1.3355 & 0.0030 & 0.0000 & 3.8021 \\
\hline & \multicolumn{5}{|c|}{ Gender and age } \\
\hline$\alpha_{0}$ & 0.8786 & 0.0020 & 0.0000 & \\
\hline$G$ & 0.2646 & 0.0016 & 0.0000 & 1.3029 \\
\hline$A_{1}$ & 1.1669 & 0.0023 & 0.0000 & 3.2120 \\
\hline$A_{2}$ & 1.5701 & 0.0026 & 0.0000 & 4.8071 \\
\hline$A_{3}$ & 1.4886 & 0.0026 & 0.0000 & 4.4308 \\
\hline$A_{4}$ & 1.4949 & 0.0035 & 0.0000 & 4.4589 \\
\hline$A_{5}$ & 2.2009 & 0.0061 & 0.0000 & 9.0334 \\
\hline
\end{tabular}

Source: own study (STATISTICA).

Since the age and the education variables are polynomial, the authors changed them into dichotomic variables (Table 1). The odds ratios for both sexes determined in the above presented models were interpreted resting on the assumption that the remaining variables were fixed. They also showed that the relation of the men's odds ratio to the women's one was the same in both urban and rural areas, on each education level and in each age group, while in reality they are not. This is why the authors estimated those models that consisted of only one explanatory variable in individual subgroups (stage III). The results of the logit model estimation with one explanatory variable $G$ (in subgroups) are to be found in Table 4.

Table 4. Estimated parameters of the employment logit models (stage III)

\begin{tabular}{|c|c|c|c|c|c|}
\hline$X_{i}$ & $\begin{array}{c}\text { Regression } \\
\text { coefficient estimator }\end{array}$ & Standard error & $p$-value & Odds ratio & $\begin{array}{l}\text { Logit model } \\
\text { (number) }\end{array}$ \\
\hline 1 & 2 & 3 & 4 & 5 & 6 \\
\hline & \multicolumn{4}{|c|}{$\begin{array}{c}\text { Gender - urban areas } \\
\chi^{2}=5,557.17, p=0.0000\end{array}$} & \multirow{3}{*}{9} \\
\hline$\alpha_{0}$ & 2.1608 & 0.0014 & 0.0000 & & \\
\hline \multirow[t]{2}{*}{$G$} & 0.1520 & 0.0020 & 0.0000 & 1.1641 & \\
\hline & & $\begin{array}{r}\text { Gender - rur } \\
\chi^{2}=18,905.84,\end{array}$ & $\begin{array}{l}\text { as } \\
0000\end{array}$ & & \multirow{3}{*}{10} \\
\hline$\alpha_{0}$ & 2.0149 & 0.0018 & 0.0000 & & \\
\hline$G$ & 0.3513 & 0.0026 & 0.0000 & 1.4209 & \\
\hline
\end{tabular}




\begin{tabular}{|c|c|c|c|c|c|}
\hline 1 & 2 & 3 & 4 & 5 & 6 \\
\hline & \multicolumn{4}{|c|}{$\begin{array}{c}\text { Gender - at most lower secondary education } \\
\qquad \chi^{2}=1,084.52, p=0.0000\end{array}$} & \multirow{3}{*}{11} \\
\hline$\alpha_{0}$ & 1.4884 & 0.0035 & 0.0000 & & \\
\hline \multirow[t]{2}{*}{$G$} & 0.1512 & 0.0046 & 0.0000 & 1.1633 & \\
\hline & & $\begin{array}{l}- \text { basic } \mathrm{v} \\
=6,723.4\end{array}$ & $\begin{array}{l}\text { educatiol } \\
000\end{array}$ & & \multirow{3}{*}{12} \\
\hline$\alpha_{0}$ & 2.3979 & 0.0023 & 0.0000 & & \\
\hline \multirow[t]{2}{*}{$G$} & -0.2336 & 0.0029 & 0.0000 & 0.7917 & \\
\hline & & $\begin{array}{l}\text {-general } \\
=9,732.5\end{array}$ & $\begin{array}{l}\text { educatio } \\
000\end{array}$ & & \multirow{3}{*}{13} \\
\hline$\alpha_{0}$ & 1.6479 & 0.0029 & 0.0000 & & \\
\hline \multirow[t]{2}{*}{$G$} & 0.4651 & 0.0048 & 0.0000 & 1.5922 & \\
\hline & $\chi^{2}=18$ & $\begin{array}{l}\text { secondar } \\
0000\end{array}$ & ational s & education & \multirow{3}{*}{14} \\
\hline$\alpha_{0}$ & 2.0661 & 0.0021 & 0.0000 & & \\
\hline \multirow[t]{2}{*}{$G$} & 0.4242 & 0.0031 & 0.0000 & 1.5283 & \\
\hline & & $\begin{array}{l}\text { nder }- \text { hi } \\
=6,002.9\end{array}$ & ation & & \multirow{3}{*}{15} \\
\hline$\alpha_{0}$ & 2.7590 & 0.0025 & 0.0000 & & \\
\hline \multirow[t]{2}{*}{$G$} & 0.3168 & 0.0041 & 0.0000 & 1.3505 & \\
\hline & & $\begin{array}{l}\text { Gender }- \\
=8,804.9\end{array}$ & 44 & & \multirow{3}{*}{16} \\
\hline$\alpha_{0}$ & 0.8389 & 0.0026 & 0.0000 & & \\
\hline \multirow[t]{2}{*}{$G$} & 0.3367 & 0.0036 & 0.0000 & 1.4003 & \\
\hline & & $\begin{array}{l}\text { Gender }- \\
=14,255 .\end{array}$ & 4 & & \multirow{3}{*}{17} \\
\hline$\alpha_{0}$ & 2.0066 & 0.0020 & 0.0000 & & \\
\hline \multirow[t]{2}{*}{$G$} & 0.3438 & 0.0029 & 0.0000 & 1.4103 & \\
\hline & & $\begin{array}{l}\text { Gender }- \\
=8,235.1\end{array}$ & 000 & & \multirow{3}{*}{18} \\
\hline$\alpha_{0}$ & 2.4160 & 0.0025 & 0.0000 & & \\
\hline \multirow[t]{2}{*}{$G$} & 0.3349 & 0.0037 & 0.0000 & 1.3978 & \\
\hline & & $\begin{array}{l}\text { Gender }- \\
=1,067.9\end{array}$ & 4 & & \multirow{3}{*}{19} \\
\hline$\alpha_{0}$ & 2.4345 & 0.0026 & 0.0000 & & \\
\hline \multirow[t]{2}{*}{$G$} & 0.1218 & 0.0037 & 0.0000 & 1.1295 & \\
\hline & & $\begin{array}{l}\text { Gender }- \\
=268.10\end{array}$ & & & \multirow{3}{*}{20} \\
\hline$\alpha_{0}$ & 2.4622 & 0.0046 & 0.0000 & & \\
\hline \multirow[t]{2}{*}{$G$} & 0.1004 & 0.0061 & 0.0000 & 1.1056 & \\
\hline & & $\begin{array}{l}r-\text { age } 6 \\
=2,292.5\end{array}$ & 000 & & \multirow{3}{*}{21} \\
\hline$\alpha_{0}$ & 3.6924 & 0.0121 & 0.0000 & & \\
\hline$G$ & -0.6283 & 0.0138 & 0.0000 & 0.5335 & \\
\hline
\end{tabular}

Source: own study (STATISTICA). 
When interpreting a logit model the transformation of the parameters $\exp \left(\alpha_{i}\right)$ is applied. Individual odds ratios inform us that men have more chance than women to find employment. The men's/women's odds ratios are shown in Figure 1. When the odds value is bigger than 1, it is the men whose odds are higher. When the odds value is less than 1 - women's odds are bigger than the men's. In case of the odds value equal 1 their chances are equal as well (therefore the line drawn at the 1 level is a reference one).

In Figure 1 the odds described as Total result from the transformation of the parameter of the model (5) - stage I. The employment odds are bigger by $26 \%$ men in comparison to women. The variables denoted as const. refer to the models with many explanatory variables. While interpreting parameters with the variable $G$ (gender) in these models we assume that other variables, i.e. the place of residence $(R)$, education groups $\left(E_{i}\right)$ and age groups $\left(A_{i}\right)$ remain constant.

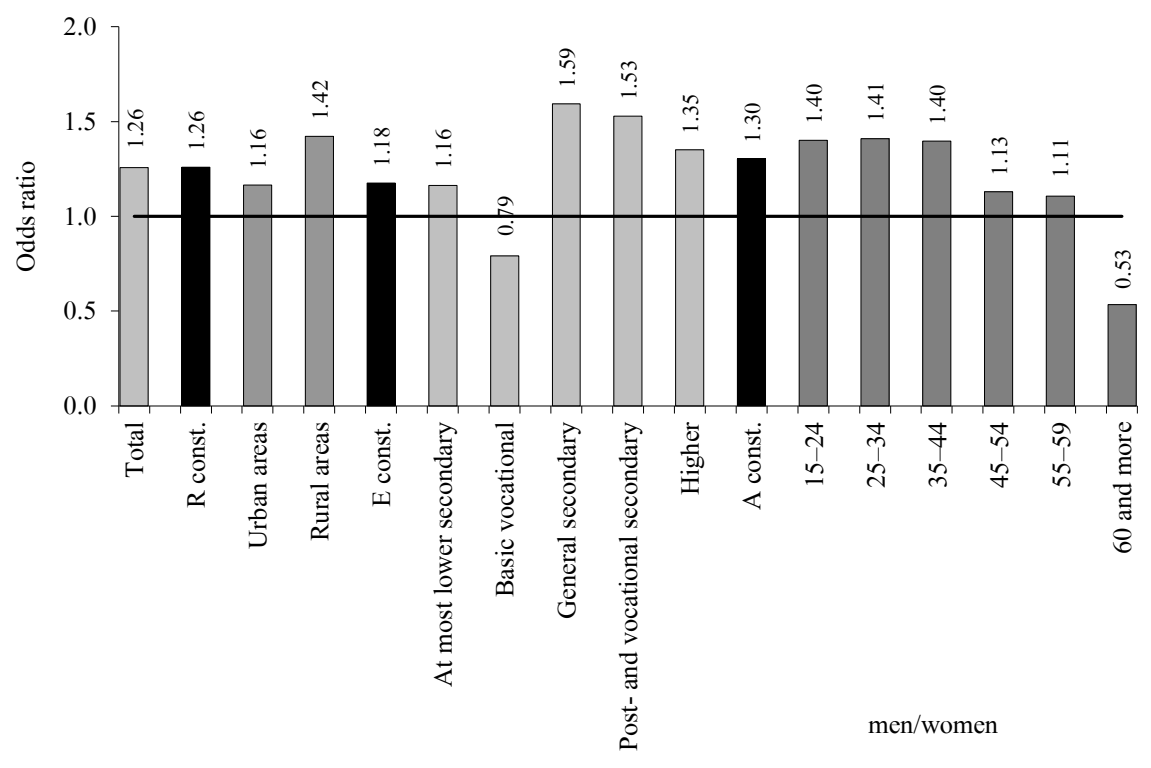

Fig. 1. The total of the men's employment odds ratios in relation to the women's ones by their place of residence, education and age in Poland in 2011

Source: own study.

Assuming that the place of residence is constant, the employment odds ratio of males in relation to females is 1.26 , which indicates that it is the same in both urban and rural areas. The 
results of modeling in the subgroups, however, show that these ratios differ (urban areas - 1.16, rural areas -1.42 ). When constructing models with one variable, analogous differences were demonstrated in reference of education and age. In the basic vocational group the odds ratio for males is $21 \%$ lower than for females, and in the $60+$ group the odds ratio for males is $47 \%$ lower than for females. In the other groups the odds ratios for males are higher than for females.

On Stage IV logit models with interactions were constructed, giving the following models:

$$
\operatorname{logit}(p)=2.0149+0.3513 \cdot G+0.1459 \cdot R-0.1993 \cdot G \times R
$$

$$
\begin{aligned}
& \operatorname{logit}(p)=1.4884+0.1512 \cdot G+0.9095 \cdot E_{1}-0.3849 \cdot G \times E_{1}+0.1595 \cdot E_{2}+ \\
& +0.3139 \cdot G \times E_{2}+0.5777 \cdot E_{3}+0.2729 \cdot G \times E_{3}+1.2706 \cdot E_{4}+0.1656 \cdot G \times E_{4} \\
& \operatorname{logit}(p)=0.8389+0.3367 \cdot G+1.1678 \cdot A_{1}+0.0071 \cdot G \times A_{1}+1.5772 \cdot A_{2}- \\
& -0.0018 \cdot G \times A_{2}+1.5956 \cdot A_{3}-0.2149 \cdot G \times A_{3}+1.6234 \cdot A_{4}-0.2363 \cdot G \times A_{4}+ \\
& +2.8536 \cdot A_{5}-0.9650 \cdot G \times A_{5}
\end{aligned}
$$

\begin{tabular}{|c|c|c|c|c|}
\hline$X_{i}$ & $\begin{array}{c}\text { Regression coefficient } \\
\text { estimator }\end{array}$ & Standard error & $p$ & Odds ratio \\
\hline \multirow[t]{2}{*}{1} & 2 & 3 & 4 & 5 \\
\hline & \multicolumn{4}{|c|}{$\begin{array}{l}\text { Gender, the place of residence and interactions } \\
\qquad \chi^{2}=24,927.83, p=0.0000\end{array}$} \\
\hline$\alpha_{0}$ & 2.0149 & 0.0018 & 0.0000 & \\
\hline G & 0.3513 & 0.0026 & 0.0000 & 1.4209 \\
\hline $\mathrm{R}$ & 0.1459 & 0.0023 & 0.0000 & 1.1570 \\
\hline \multirow[t]{2}{*}{$G \times R$} & -0.1993 & 0.0033 & 0.0000 & 0.8193 \\
\hline & \multicolumn{4}{|c|}{$\begin{array}{l}\text { Gender, education and interactions } \\
\chi^{2}=269,634.89, p=0.0000\end{array}$} \\
\hline$\alpha_{0}$ & 1.4884 & 0.0035 & 0.0000 & \\
\hline G & 0.1512 & 0.0046 & 0.0000 & 1.1633 \\
\hline$E_{1}$ & 0.9095 & 0.0042 & 0.0000 & 2.4831 \\
\hline$G \times E_{1}$ & -0.3849 & 0.0054 & 0.1224 & 0.6805 \\
\hline$E_{2}$ & 0.1595 & 0.0045 & 0.0000 & 1.1729 \\
\hline$G \times E_{2}$ & 0.3139 & 0.0066 & 0.7281 & 1.3687 \\
\hline$E_{3}$ & 0.5777 & 0.0041 & 0.0000 & 1.7819 \\
\hline$G \times E_{3}$ & 0.2729 & 0.0055 & 0.0000 & 1.3138 \\
\hline$E_{4}$ & 1.2706 & 0.0043 & 0.0000 & 3.5629 \\
\hline$G \times E_{4}$ & 0.1656 & 0.0062 & 0.0000 & 1.1801 \\
\hline
\end{tabular}

The results of the logit model estimation with one explanatory variable $G$ (in subgroups) are to be found in Table 5 .

Table 5. Estimated parameters of the employment logit models with interactions (stage IV) 


\begin{tabular}{|l|r|c|c|c|}
\hline \multicolumn{1}{|c|}{1} & 2 & 3 & 4 & 5 \\
\hline & \multicolumn{3}{|c|}{$\begin{array}{c}\text { Gender, age and interactions } \\
\chi^{2}=517,798.14, p=0.0000\end{array}$} \\
\hline$\alpha_{0}$ & 0.8389 & 0.0026 & 0.0000 & \\
\hline $\mathrm{G}$ & 0.3367 & 0.0036 & 0.0000 & 1.4003 \\
\hline$A_{1}$ & 1.1678 & 0.0033 & 0.0000 & 3.2148 \\
\hline$G \times A_{1}$ & 0.0071 & 0.0046 & 0.1224 & 1.0071 \\
\hline$A_{2}$ & 1.5772 & 0.0036 & 0.0000 & 4.8412 \\
\hline$G \times A_{2}$ & -0.0018 & 0.0052 & 0.7281 & 0.9982 \\
\hline$A_{3}$ & 1.5956 & 0.0037 & 0.0000 & 4.9314 \\
\hline$G \times A_{3}$ & -0.2149 & 0.0052 & 0.0000 & 0.8066 \\
\hline$A_{4}$ & 1.6234 & 0.0053 & 0.0000 & 5.0701 \\
\hline$G \times A_{4}$ & -0.2363 & 0.0071 & 0.0000 & 0.7895 \\
\hline$A_{5}$ & 2.8536 & 0.0124 & 0.0000 & 17.3499 \\
\hline$G \times A_{5}$ & -0.9650 & 0.0142 & 0.0000 & 0.3810 \\
\hline
\end{tabular}

Source: own study (STATISTICA).

Basing on parameters of these models we can calculate the ratios of men's economical activity odds in relation to the women belonging to the same subgroup (the same place of residence, the same age group, the same level of education). In model (22) the ratio of men's professional activity odds compared to the women's in the group of rural area residents equals 1.4209 , while in the case of city-dwellers it is $1.1641(1.4209 \cdot 0.8193)$. The obtained values are identical to the results in models ( 9 and 10). The same situation is in the case of models (23) and (24).

\section{Conclusions}

There are two main conclusions from the above study. The first is of an empiric nature, while the second's character is methodological. The situation of women and men on the Polish labor market in 2011 was not the same. Men usually enjoyed higher employment odds, however they varied according to their place of residence, education and age.

We can say that if it is possible to build logit models for individual groups (assuming that the data are available and a group is of a sufficient size) or with interactions, we can obtain more accurate results concerning the problem being investigated. We have shown this by conducting the stages III and IV of our study. We have found that the model with one explanatory variable in subgroup or the model with interactions gives more information than the model with many explanatory variables. 


\section{Notes}

${ }^{1}$ See Cuesta, Martín (2009); Blazy, Chopard (2012); García-Sánchez et al. (2013).

${ }^{2}$ For more details see Hosmer, Lemeshow (2000); Kleinbaum, Klein (2002); Cramer (2002); Agresti (2002); Wiśniewski (2011).

${ }^{3}$ See Fijorek, Sokołowski (2012).

${ }^{4}$ For more details see Meyer (1990); Richard (1997); Kostaki, Ioakimoglou (1998); Lučkaničová et al. (2012); Jarosova et al. (2004); Markowicz, Stolorz (2009b); Bieszk-Stolorz (2011).

${ }_{5}^{5}$ More about the coding of variables Markowicz and Stolorz (2009a).

${ }^{6}$ Theory about measurement scales presented by Stevens (1946).

\section{References}

Agresti, A. (2002). Categorial Data Analysis. Second Edition. Hoboken, NJ: John Wiley \& Sons.

Bieszk-Stolorz, B. (2011). Economic Activity of the Disabled in Poland in 2010. Folia Oeconomica Stetinensia, 10 (18) 2011/2, 128-137.

Blazy, R. \& Chopard, B. (2012). (Un)secured debt and the likelihood of court-supervised reorganization. European Journal of Law and Economics, 34, 45-61.

Cramer, J.S. (2002). The Origins of Logistic Regression. Working Paper. Tinbergen Institute, No. 119/4, http://dare.uva.nl/document/204 (15.09.2012).

Cuesta, M.B. \& Martín, N.E.R. (2009). Part-time employment: a comparative analysis of Spain and the Netherlands. European Journal of Law and Economics, 28, 223-256.

Fijorek, K. \& Sokołowski, A. (2012). Separation-Resistant and Bias-Reduced Logistic Regression: STATISTICA Macro. Journal of Statistical Software.

García-Sánchez, I.-M., Rodríguez-Domínguez, L. \& Gallego-Álvarez, I. (2013). CEO qualities and codes of ethics. European Journal of Law and Economics, 35, 295-312.

Hosmer, D.W. \& Lemeshow S. (2000). Applied Logistic Regression. New York: John Wiley \& Sons.

Jarosova, E., Mala, I., Esser, M. \& Popelka, J. (2004). Modelling Time of Unemployment via Long-Location-Scale Model. COMPSTAT 2004 Symposium, Physica-Verlag/Springer. http://most.ujep.cz/ popelka/compstat.pdf (15.12.2012).

Kleinbaum, D.G. \& Klein, M. (2002). Logistic Regression. A Self-Lerning Text. New York: Springer-Verlag. 
Kostaki, A. \& Ioakimoglou E. (1998). Demographic Factors Affecting Long-Term Unemployment in Greece. Proceedings of the International Labour Market Conference, Aberdeen, Scotland.

Labour Force Survey in Poland IV Quarter 2011, (2012). Statistical Information and Elaborations, Warszawa, Central Statistical Office.

Lučkaničová, M., Ondrušeková, I. \& Rešovský, M. (2012). Employment modelling in Slovakia: Comparing Logit models in 2005 and 2009. Economic Annals, LVII (192). DOI:10.2298/ EKA1292025L.

Markowicz, I. \& Stolorz, B. (2009a). Interpretation of Parameters of the Logistic Regression and Ways of Coding of Explanatory Variables. Polish Journal of Environmental Studies, 18 (3B), 252-256.

Markowicz, I.\& Stolorz, B. (2009b). The Applications of Logistic Regression for Analysing the Odds of Commencing Employment. In: Quantitative Methods in Regional and Sectoral Analysis, eds. D. Witkowska, M. Łatuszyńska (pp. 85-99). Szczecin: Zapol.

Meyer, B.D. (1990). Unemployment Insurance and Unemployment Spells. Econometrica, $58(4), 757-782$.

Richard, J.-L. (1997). Unemployment Among Young People of Foreign Origin in France: Ways of Measuring Discrimination. In: On the way to a multicultural society? The Siena Group Seminar on Social Statistics (pp. 101-135). Bern: Bundesamt für Statistik.

Stevens, S.S. (1946). On the Theory of Scales Measurement. Science, 103 (2684), 677-680.

Wiśniewski, J.W. (2011). Dilemmas of Economic Measurements in Weak Scales. Folia Oeconomica Stetinensia, 10 (18), 50-59.

www.jstatsoft.org/v47/c02/paper (2.06.2012). 